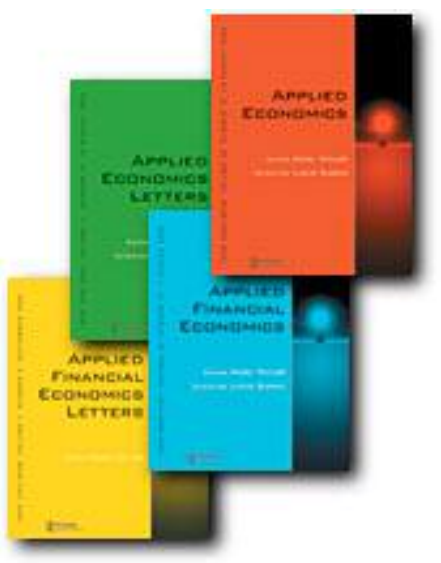

\title{
MACROECONOMIC UNCERTAINTY AND BANKS' LENDING DECISIONS: THE CASE OF ITALY
}

\begin{tabular}{|r|l|}
\hline Journal: & Applied Economics \\
\hline Manuscript ID: & APE-06-0075.R1 \\
\hline Journal Selection: & Applied Economics \\
\hline JEL Code: & $\begin{array}{l}\text { E44 - Financial Markets and the Macroeconomy < E4 - Money and } \\
\text { Interest Rates < E - Macroeconomics and Monetary Economics, G28 } \\
\text { and Services < G - Financial Economics, G21 - Banks } \mid \text { Other } \\
\text { Depository Institutions|Mortgages < G2 - Financial Institutions and } \\
\text { Services < G - Financial Economics }\end{array}$ \\
\hline Keywords: & bank, business cycle, uncertainty, lending decisions, garch \\
\hline
\end{tabular}

\section{S) ScholarONE" \\ Manuscript Central}




\title{
MACROECONOMIC UNCERTAINTY AND BANKS’ LENDING DECISIONS: THE CASE OF ITALY
}

\author{
Mario Quagliariello* \\ Bank of Italy and University of York (UK)
}

\begin{abstract}
This paper discusses the role that macroeconomic uncertainty plays in banks' decisions on the optimal asset allocation. Following the portfolio model proposed by Baum et al. (2005), the paper aims at disentangling how Italian banks choose between loans and risk-free assets when uncertainty on macroeconomic conditions increases.

The econometric results confirm that macroeconomic uncertainty is a significant determinant of banks' investment decisions, also after controlling for other factors. In periods of increasing turmoil, banks' ability to accurately forecast future returns is hindered and herding behaviour tends to emerge, as witnessed by the reduction of the crosssectional variance of the share of loans held in portfolio.
\end{abstract}

JEL classification numbers: E44, G21, G28

Keywords: bank, business cycle, uncertainty, lending decisions, GARCH

* Banca d'Italia, Banking and Financial Supervision and University of York, Department of Economics and Related Studies.

Address correspondence to: Mario Quagliariello - Banca d'Italia - Via Milano, 53 - 00184 Roma ITALY. Ph.: +39-0647923980 - Fax: +39-0647925059. E-mail: mario.quagliariello@bancaditalia.it 


\section{INTRODUCTION}

In recent years, the increasing interest in financial stability as an autonomous policy target, along with monetary and microeconomic stability, has encouraged the analyses of the linkages between the macroeconomic environment and the soundness of the banking system.

This stream of work is usually referred to as research on the "procyclicality" of banks' operations. Most of these studies use the current status of macroeconomic conditions as the main exogenous cause for the state of health of banks. The goal is to assess to what extent macroeconomy affects banks' performance (cyclicality) and whether, in turn, banks' reaction to changing macroeconomic conditions further affects the macroeconomy, reinforcing cyclical fluctuations (procyclicality). These studies generally confirm that banks' balance sheets are affected, simultaneously or with some delay, by the business cycle and claim that banks’ behaviour is procyclical.

However, the change in banks' behaviour through the business cycle is not explicitly modelled, but it is simply inferred looking at the reduced-form relationships between micro and macro variables. Bank-specific indicators are frequently included as regressors, but they are only used as control variables, while the focus rests on the proxies for macroeconomic conditions. Furthermore, apart from some recent papers on North-American banks, no study assesses the role that macroeconomic uncertainty plays in determining banks' behaviour: in other words, no attention is paid on the second moments of macroeconomic variables.

Summing up, the current state of the art is unsatisfactory for two main reasons: i) no attempt is made in order to model how banks' management varies in changing 
macroeconomic environments; ii) the effect of the uncertainty regarding future macroeconomic conditions is typically neglected.

This paper tries to fill these gaps. In particular, it aims at disentangling which are the determinants of banks' willingness to invest in risky loans as opposed to riskfree assets and understanding whether macroeconomic uncertainty plays a role in this choice. Following the portfolio model proposed by Baum et al. (2005), which provides an explicit link between the cross-bank dispersion of the share of loans held in portfolio and uncertainty, the paper discusses how Italian banks choose between loans and riskfree assets when the uncertainty of macroeconomic conditions increases. Given the substantial differences between North-American and European banking sectors, this paper can provide useful insights on the reliability of the model when a different sample of intermediaries is used.

An important innovation of this work is that, with respect to Baum et al., who neglect the role of idiosyncratic factors in the econometric specification, the impact of macroeconomic uncertainty is assessed after controlling for bank-specific sources of uncertainty. In particular, introducing an appropriate proxy, I explicitly consider the importance of idiosyncratic uncertainty in determining banks’ portfolio decisions.

This paper also enriches the existing evidence employing different proxies for macroeconomic uncertainty; this also allows me to extensively assess the robustness of the results. Finally, the paper provides evidence on banks' sub-samples, testing whether the theory is valid at different levels of aggregation.

The econometric results confirm that macroeconomic uncertainty plays a significant role in Italian banks’ investment decisions. In periods of increasing turmoil, 
banks receive noisier signals on the expected returns of loans and, therefore, tend to behave more homogenously, as shown by the reduction of the loan-to-asset ratio crosssectional dispersion. Idiosyncratic uncertainty is also relevant and its coefficient takes on a positive sign. When returns on specific investments are less easily predictable, better informed banks can exploit their competitive advantage and behave in a different way with respect to poorly informed intermediaries.

The remainder of the paper is organized as follows. Section 2 and 3 provide a short survey of the literature and describe the portfolio model used in the analysis. Section 4 reports the empirical results. Conclusions are provided in Section 5.

\section{REVIEW OF THE LITERATURE}

There is a huge literature supporting the hypothesis that macroeconomic conditions affect the performance of the banking sector ${ }^{1}$. Most of the work focuses on measures of central tendency rather than on those of uncertainty.

Salas and Saurina (2002), for instance, observe that macroeconomic shocks are quickly transmitted to Spanish banks' balance sheets. During economic booms, intermediaries tend to expand their lending activity, often relaxing their selection criteria; in the following downturns, bad loans remarkably increase, producing losses. Using a panel of Italian banks, Quagliariello (in press, b) finds that loan loss provisions and bad debts increase in bad macroeconomic times. Pesola (2001) shows that the high level of both corporate and households' indebtedness, along with shortfalls of GDP growth below forecast levels, contributed to the banking crises in the Nordic countries. Similar evidence is provided in cross-country comparisons by Bikker and Hu (2002), 
Laeven and Majnoni (2003) and Valckx (2003). Gambera (2000) and Meyer and Yeager (2001) document that a small number of macroeconomic variables are good predictors for non-performing loan ratio in the US. Similarly, Hoggarth et al. (2005) provide evidence of a clear link between the state of the UK business cycle and banks' writeoffs.

While there is an extensive literature on the investment decisions of nonfinancial firms under macroeconomic instability (for a survey, see Carruth et al. (2000)), the role of uncertainty regarding future macroeconomic conditions has been largely neglected for banks instead. This is an important issue, since banks' investments fuel those of the rest of the economy. To the best of my knowledge, there are only two recent papers that investigated this issue.

Baum et al. (2005) use a portfolio model and a sample of US banks. Their results suggest that when macroeconomic uncertainty - proxied by the conditional variance of a relevant macroeconomic variable - increases, the cross-bank dispersion of the share of risky loans to total assets diminishes, as uncertainty hinders bank ability to foresee investment opportunities. In other words, they claim that higher uncertainty makes the signals on expected returns noisier. Uncertainty would therefore push banks to rebalance the composition of their assets according to new (worse) signals provided by credit markets, adversely affecting the allocation of financial resources. This fosters herding behaviour and leads banks to behave more homogeneously than in quiet periods. This evidence is robust to the inclusion of several control variables and holds for total bank loans as well as for their main components.

\footnotetext{
${ }^{1}$ For a survey, see Quagliariello (in press, a).
} 
Adopting the same approach, Garcia and Calmes (2005) reach similar conclusions for the Canadian banking system. Their results, though based on univariate regression, confirm that there is a negative relationship between the proxy for macroeconomic uncertainty and the cross-bank variance of the loan-to-asset ratio. In other words, also Canadian intermediaries show herding behaviour when they deal with more pronounced aggregate uncertainty.

\section{BANKS' LENDING DECISIONS UNDER UNCERTAINTY: BAUM, CAGLAYAN AND OZKAN'S MODEL}

Adapting the framework for non-financial firms' investments presented by Beaudry et al. (2001), Baum et al. (2005) propose a model that describes how banks set the optimal composition of their portfolios.

In their scheme, banks’ managers operate in a risky environment and, in each period, can invest deposits into two different assets: loans and bonds. The investment in bonds is assumed free of default risk, but it bears market risk since the value of the securities may change as a result of varying market conditions. This risk is predictable and, more importantly, it can be managed and hedged. The return of such an investment is the risk free rate $\left(r_{f}\right)$.

Loans to customers entail the exposure to both market and default risk. The latter is the result of an idiosyncratic component - due the probability that the specific customer will default in the future without repaying the debt - and systemic factors, correlated to the status of the economy. In fact, it is well documented that in bad macroeconomic times the riskiness of bank portfolios tends to increase. 
For bank $\mathrm{i}$ at time $\mathrm{t}$, the investment in risky loans provides a stochastic return $\left(\mathrm{r}_{\mathrm{i}}\right)$ equal to the risk free rate plus a risk premium $\left(\mathrm{rp}_{\mathrm{i}}\right)$, which is equal for all loans assumed to be homogeneous - and does not depend on the riskiness of the single borrower ${ }^{2}$ :

$$
r_{i}=r_{f}+r p_{i}
$$

The risk premium has an expected value $\mathrm{E}\left(\mathrm{rp}_{\mathrm{i}}\right)=\rho$ and a variance $\operatorname{Var}\left(\mathrm{rp}_{\mathrm{i}}\right)=\sigma_{\varepsilon}^{2}$.

The return on loans can thus be expressed as:

$$
r_{i}=r_{f}+\rho+\varepsilon_{i}
$$

where $\varepsilon_{\mathrm{i}}$ is a random component distributed as $\mathrm{N}\left(0, \sigma_{\varepsilon}^{2}\right)$. Baum et al. also assume that each bank has a specific portfolio with different riskiness structure and, hence, the random components of return across different intermediaries are not correlated $\left(\mathrm{E}\left[\varepsilon_{\mathrm{i}} \varepsilon_{\mathrm{j}}\right]=0\right)$.

Banks’ managers deal with a portfolio optimization problem. They rebalance the composition of their assets in order to obtain the preferred combination of risk and expected return. According to their utility functions, they choose the shares $\alpha_{i}$ and (1$\alpha_{i}$ ) of their assets to invest respectively in loans and bonds. However, before taking the decision, banks observe neither the actual risk premium nor the random component $\varepsilon_{\mathrm{i}}$, but only a noisy signal of them:

$$
S_{i}=\varepsilon_{i}+v,
$$

\footnotetext{
${ }^{2}$ The subscript $\mathrm{t}$ is omitted since the model describes a one period problem.
} 
where $v$ is a random variable independent of $\varepsilon_{\mathrm{i}}$ with a normal distribution $\mathrm{N}(0$, $\sigma^{2}{ }_{v}$ ). By assumption, the noise component ( $\left.v\right)$ of the signal banks receive is identical for all of them, while the overall signals remain different across intermediaries because of $\varepsilon_{i}$. In fact, even though all banks are believed to have the ability to overcome asymmetric information problems, cross-sectional differences in their private information set remain. In principle, $v$ may be observed and uncertainty eliminated if all banks would share their private information. However, information sharing is unlikely to hold in the credit market.

The noise $v$ can be interpreted as the degree of uncertainty on future macroeconomic conditions. Its impact on banks is homogeneous, regardless of managers' ability to predict the random component of loan return $\varepsilon_{\mathrm{i}}$. When macroeconomic uncertainty increases, the higher variance of $v$ makes the estimates of the true return of loans less precise. The assumption of independence between $v$ and $\varepsilon_{\mathrm{i}}$ is now clearer; indeed, it is plausible that the aggregate macroeconomic shock is not correlated with the idiosyncratic component of loan returns.

In order to determine the expected return on loans $\left(\mathrm{r}_{\mathrm{i}}\right)$, bank managers have to predict the value of $\varepsilon_{\mathrm{i}}$. Without observing the noisy signal, banks' unconditional forecast on $\varepsilon_{\mathrm{i}}$ would be the mean of its distribution, i.e. zero. However, banks do observe the signal and can extract additional information from it. The expected value of the return from loans conditional upon $S_{i}, E\left[\varepsilon_{i} \mid S_{i}\right]$, is assumed to be a constant proportion $(\lambda)$ of the signal, where $\lambda$ represents a linear regression coefficient of $\varepsilon_{\mathrm{i}}$ on $\mathrm{S}_{\mathrm{i}}$ : 
$E\left[\varepsilon_{i} \mid S_{i}\right]=\lambda S_{i}=\lambda\left(\varepsilon_{i}+v\right)$, where $\lambda=\frac{\sigma_{\varepsilon}^{2}}{\sigma_{\varepsilon}^{2}+\sigma_{v}^{2}}$

The conditional expected return of the i-th bank's portfolio $E\left[R_{i} \mid S_{i}\right]$ is therefore:

$$
\begin{aligned}
& E\left[R_{i} \mid S_{i}\right]=\alpha_{i}\left(r_{f}+\rho+E\left[\varepsilon_{i} \mid S_{i}\right]\right)+\left(1-\alpha_{i}\right) r_{f}= \\
& \alpha_{i}\left(r_{f}+\rho+\lambda\left(\varepsilon_{i}+v\right)\right)+\left(1-\alpha_{i}\right) r_{f}
\end{aligned}
$$

and the conditional variance $\operatorname{Var}\left[\mathrm{R}_{\mathrm{i}} \mid \mathrm{S}_{\mathrm{i}}\right]$ is:

$$
\operatorname{Var}\left[R_{i} \mid S_{i}\right]=\alpha_{i}^{2} \lambda \sigma_{v}^{2}
$$

Risk-averse banks are assumed to have the following utility function:

$$
E\left[U_{i} \mid S_{i}\right]=E\left[R_{i} \mid S_{i}\right]-\frac{\omega}{2} \operatorname{Var}\left[R_{i} \mid S_{i}\right]
$$

which is increasing in expected return and decreasing in return volatility (and $\omega$ is the coefficient of risk aversion).

Employing the portfolio's mean/variance equations, it is straightforward to derive the optimal loan-to-asset ratio $\left(\alpha_{i}\right)$ for bank i and the associated cross-sectional dispersion:

$$
\begin{gathered}
\alpha_{i}=\frac{\rho+\lambda S_{i}}{\omega \lambda \sigma_{v}^{2}} \\
\operatorname{Var}\left(\alpha_{i}\right)=\frac{\sigma_{\varepsilon}^{2}}{\omega^{2} \sigma_{v}^{4}}
\end{gathered}
$$

The variance of the cross-sectional distribution of the loan-to-asset ratio is negatively correlated to the level of macroeconomic uncertainty $\sigma^{2}{ }_{v}$. Indeed, taking the first derivative of the variance of $\alpha_{i}$ with respect to $\sigma^{2}{ }_{v}$, it derives: 


$$
\frac{\partial \operatorname{Var}\left(\alpha_{i}\right)}{\partial \sigma_{v}^{2}}=-\frac{2 \sigma_{\varepsilon}^{2}}{\omega^{2} \sigma_{v}^{6}}<0,
$$

which provides a testable implication of the hypothesis that the cross-sectional variance of the loan-to-asset ratio narrows as macroeconomic uncertainty increases.

The variance of $\alpha_{i}$ instead widens when the variance of the idiosyncratic component increases:

$$
\frac{\partial \operatorname{Var}\left(\alpha_{i}\right)}{\partial \sigma_{\varepsilon}^{2}}=\frac{1}{\omega^{2} \sigma_{v}^{4}}>0
$$

Therefore, it is essential to control for this component when testing for the impact of macroeconomic uncertainty. The choice of a proper proxy for idiosyncratic risk may however represent a major problem.

In sum, I have two hypotheses to test:

Hypothesis 1): When macroeconomic uncertainty increases, banks tend to allocate assets in their portfolios more homogeneously (the variance of $\alpha$ across banks reduces);

Hypothesis 2): When idiosyncratic uncertainty increases, banks tend to behave more heterogeneously (the variance of $\alpha$ across banks rises).

\section{EMPIRICAL EVIDENCE}

\subsection{Data}

The impact of macroeconomic uncertainty on banks' lending decisions can be empirically tested using the following specification: 
$\operatorname{Var}_{t}\left(L T A_{i, t}\right)=a+b \sigma_{v, t}^{2}+c \sigma_{\varepsilon, t}^{2}+u_{t}$

where $\mathrm{LTA}_{\mathrm{i}, \mathrm{t}}$ is the loan-to-asset ratio and $\operatorname{Var}_{\mathrm{t}}\left(\mathrm{LTA}_{\mathrm{i}, \mathrm{t}}\right)$ is its cross-sectional variance at time $t ; \sigma^{2}{ }_{v}$ represents macroeconomic uncertainty evaluated at time $t ; \sigma^{2}$ is the idiosyncratic uncertainty and $\mathrm{u}_{\mathrm{t}}$ is the error term.

The cross-bank variance of the LTA is built up using quarterly data (1990q12005q1) for a sample of more than 900 intermediaries, representing virtually the entire Italian banking system in each quarter. Before 1990 the Italian credit market was intensely regulated by public authorities for both monetary policy and supervisory purposes $^{3}$. The results of the analysis would be therefore not reliable. Furthermore, formal Chow tests reject at the 1 per cent level the null hypothesis of no structural break in 1990 and advice to split the sample.

Overall, the dataset includes 58.146 bank/quarter observations. A summary of the characteristics of the sample is provided in table 1.

\footnotetext{
${ }^{3}$ For example, as far as monetary policy is concerned, in 1986q1-1986q2 and 1987q4-1988q1 ceilings on the supply of credit that each bank may provide to the aggregate of its customers (so-called massimale sugli impieghi) were still in use. These constraints, intended for controlling liquidity and aggregate demand, limited banks’ ability to expand their shares in the loan market. As a result, even in the absence of specific obligations for banks to subscribe Treasury bonds, the banking system’s demand for bonds increased (see Cotula, 1989). Also supervisory rules were particularly strict. According to the banking law, intermediaries were classified as retail banks, providing only short-term credit, and medium and long-term credit institutions. Until 1990, when the Bank of Italy decided to liberalize banks' branch networks, the opening of new branches was limited by the system of "branch plans”. These legal barriers between different categories of banks and the administrative constraints on the opening of branches were an obstacle to the enlargement of banks’ activity (see Ciocca, 2004).
} 


\section{[Insert table 1 here]}

Accounting ratios for the individual institutions are built up using the statistics that intermediaries are required to report to the Bank of Italy; the macroeconomic variables are drawn from the OECD main economic indicators (MEI) dataset.

The evolution of the loan-to-asset ratio over time is drawn in figure 1 . The ratio shows a clear ascending trend, witnessing the increasing liberalization of the Italian credit market and the competitive incentives to improve market positions that banks received during the '90s. Also, the gradual reduction of interest rates made the subscription of securities, especially government bonds, less profitable for banks.

\section{[Insert figure 1 here]}

Given the relevance of this trend, I estimate model (a) using the coefficient of variation rather than the variance of the LTA in order to have a unit-free measure of dispersion:

$$
C V_{t}\left(L T A_{i, t}\right)=a+b \sigma_{v, t}^{2}+c \sigma_{\varepsilon, t}^{2}+u_{t}
$$

Table 2 shows the main descriptive statistics for the loan-to-asset ratio (LTA), its variance (STDLTA) and coefficient of variation (CVLTA). Data refer to the whole banking system as well as to 5 dimensional breakdowns ${ }^{4}$.

\section{[Insert table 2 here]}

\footnotetext{
${ }^{4}$ According to the classifications provided by the Bank of Italy, banks are grouped into five categories depending on the size of their total assets: major banks (total assets greater than 45 billion euros), large (total assets between 20 and 45 billion euros), medium-sized (7-20), small (1-7), minor (total assets up to 1 billion euros).
} 
Looking at the table, there is no evidence of a clear relationship between LTA dispersion and bank size during the fifteen years under observation. Fig. 2 provides a clearer picture of this relationship.

\section{[Insert figure 2 here]}

Large banks are those that, in the period under examination, have the smaller cross-sectional dispersion of the indicator. By contrast, small banks are those that behave more heterogeneously. However, in the last two years, major and large banks show the highest levels of the variation coefficients. This may indicate that recently large banks have adopted more diversified growth strategies.

Certainly, the evolution of LTA is also affected by the consolidation process of the Italian banking system. Indeed, after M\&As, the newly established banking groups tended to reorganize their portfolios and, in some cases, to allocate specific assets to specialized entities of the group. This is particularly evident for major banks in 1995 and 1998.

\subsection{Measuring macroeconomic uncertainty}

There are several ways to measure macroeconomic uncertainty. According to Driver et al. (2004) and Sepulveda-Umanzor (2004) two approaches are dominant: the “survey based approach” (or cross-section dispersion forecasts) and the “model based approach” (or time series conditional volatility).

The first one exploits the surveys on the expectations on relevant macroeconomic variables and obtains a measure of uncertainty as the intra-personal dispersion of the expectations. A main shortcoming of this methodology is that the intra-personal dispersion (i.e., the true uncertainty) is not observable and may only be 
approximated using the inter-personal dispersion of the expectations (the disagreement across forecasters). This procedure is reliable only if the latter measure is a valid proxy for the former (Zarnowitz and Lambros, 1987; Bomberger, 1996). In fact, it is possible that, even if each forecaster is extremely uncertain about future events, all of them submit similar estimates. Then, this measure would fail to capture the amount of existing uncertainty (Grier and Perry, 2000).

The second metric is obtained employing the realised values of the macroeconomic variables in order to get statistical or econometric estimations of their variability. Even though many measures of uncertainty can be implemented from timeseries (unconditional variance, one-step ahead forecast errors, etc.), the conditional heteroskedasticity estimated with $\mathrm{G}(\mathrm{ARCH})$ models is one of the most widely used (Engle, 1982; Bollerslev, 1986). In the case of GARCH(1,1), the conditional variance of a variable $\left(\mathrm{h}_{\mathrm{t}}\right)$ can be estimated, along with its mean, using the following specification:

$$
\begin{aligned}
& y_{t}=x_{t} \beta+\eta_{t} \\
& h_{t}=c+a \eta_{t-1}^{2}+g h_{t-1}
\end{aligned}
$$

Provided that the coefficients on the ARCH and GARCH effects are statistically significant, the fitted values of $h_{t}$ can be employed as proxies for uncertainty. This approach has two potential drawbacks. First, as highlighted by Sepulveda-Umanzor (2004), "rather than measuring uncertainty, the model based approach really measures volatility. The former is a feature that forward looking agents face when confronting any decision, the latter is a characteristic of the data once uncertainty has been solved”. Second, the time-series used in the analyses do not necessarily exhibit (G)ARCH processes. 
Given the complexity of defining reliable proxies for uncertainty, ideally one would use both the approaches recalled above. However, due to lack of data on survey outputs, in this paper I use the latter and calculate the conditional heteroskedasticity of relevant macroeconomic variables as proxies for macroeconomic uncertainty ${ }^{5}$. In spite of some of its shortcomings, this approach is commonly used in the literature. As a robustness check, I also use the one-step ahead forecast error as an alternative metric.

I use the OECD monthly series of the composite leading indicator, industrial production and consumer price index (CPI). The time span of the series is 1975m12005m3. The composite leading indicator is an aggregate series that shows a leading relationship with the reference series for the business cycle in a given country; the indicator can therefore be used as an early signal of the main turning points of the aggregate economic activity. The industrial production index measures the increases and decreases in production output. Given the impact that fluctuations in the level of industrial activity have on the remainder of the economy, the variable is frequently used as a short-term indicator of the business cycle. The indicator is seasonally adjusted.

As pointed out by Carruth et al. (2000), often the literature that uses conditional variance as a measure of uncertainty assumes, rather than testing, both the stationarity of the time-series and the presence of (G)ARCH effects. In this paper, the original monthly series are transformed in order to obtain the monthly percentage rates of change of industrial production (INDPRODC), CPI (INFL) and the leading indicator (LEADINDC). The transformation allows to work with stationary series (table 3) and

\footnotetext{
${ }^{5}$ For Italy, a quarterly survey on firms' expectations regarding future inflation is available only since December 1999.
} 
consistently estimate their conditional variance. For each variable, the specification of the auxiliary regression employed for the ADF tests has been selected via a general tosimple-approach, as suggested by Enders (1995), starting with 6 lags, a trend and a constant.

\section{[Insert table 3 here]}

The results of the Lagrange Multiplier tests for null hypothesis of no ARCH effects suggest that both industrial production growth and CPI inflation exhibit significant conditional heteroskedasticity; for the series of the composite leading indicator, the test is not significant instead (table 4). Accordingly, I exclude the latter variable from the analysis and estimate the GARCH models only for the former two variables.

\section{[Insert table 4 here]}

Table $5 \mathrm{a}$ and $5 \mathrm{~b}$ provide the results of the unrestricted $\operatorname{GARCH}(1,1)$ models performed on industrial production growth (INDPRODC) and inflation (INFL). In the variance equation, the coefficients of the ARCH and GARCH effects are significant respectively at the 5 and 1 per cent levels for both the variables.

[Insert tables 5a, 5b here]

The conditional variance $\left(h_{t}\right)$ derived from each GARCH model is finally averaged to quarterly frequency in order to obtain the measure of macroeconomic uncertainty 
(INDPRVA and INFLVA) ${ }^{6}$.

These variables enter in model (b) as generated regressors. They measure with noise the true, though unobservable, regressor $\left(\sigma_{v}^{2}\right)$. The estimates for model (b) can therefore be biased and inconsistent if the ARCH-type model employed is misspecified.

Therefore, I use the Lagrange Multiplier in order to test for neglected serial correlation of up to order 12 in the standardized squared residuals of the ARCH models. The LM tests cannot reject the null hypothesis of no additional ARCH effects at any conventional level. These results confirm that the specification is able to capture all the conditional heteroskedasticity present in industrial production and inflation series and corroborate the choice of the parsimonious GARCH $(1,1)$. The correct specification of the generating regressions should ensure parameter consistency also in the derived model (Pagan and Ullah, 1988).

Figures 3 and 4 plot the coefficient of variation of the loan-to-asset ratio and the measures of industrial production and inflation uncertainty respectively.

[Insert figures 3, 4 here]

In the aftermath of the EMS crisis in the first half of the ' 90 s, the coefficient of variation of the LTA ratio reaches the lowest figure. In the same period, macroeconomic - especially inflation - uncertainty rises markedly.

\footnotetext{
${ }^{6}$ Strictly speaking this measure is not the quarterly volatility, but the average of the monthly volatilities in a given quarter. As an alternative measure I also use the quarter-end conditional variance. Results are unchanged.
} 
The dispersion of the LTA shows a significant increase during the second half of the decade, a period characterized by the vigorous process of consolidation, which encouraged banks to look for new markets and more profitable activities. This may help explain more heterogeneous behaviour across intermediaries. Both measures of economic uncertainty show a descending trend during the '90s; for inflation, this tendency is particularly noticeable at the end of those years. This is likely one of the benefits of the EMU convergence process.

\subsection{Econometric specification and results}

The final specification of model (b) is the following:

$$
\begin{aligned}
& C V_{t}\left(\text { LTA }_{i, t}\right)=a+b h_{t}+c \text { STDNPL }_{t+1}+d \mathrm{INFL}_{t}+ \\
& +e \mathrm{INDPRODC}_{t}+f \text { SHAREC }_{t}+u_{t}
\end{aligned}
$$

where $h_{t}$ is the estimated conditional variance of either industrial production growth (INDPRVA) or inflation (INFLVA). According to hypothesis 1), the expected sign of the coefficient of this regressor is negative. Along with the proxy for macroeconomic uncertainty $\left(h_{t}\right)$, I also introduce some control variables.

First, I employ the 1-quarter lead of the cross-sectional variance of the nonperforming loan ratio (STDNPL). This indicator is a proxy for the idiosyncratic uncertainty. If at time t the idiosyncratic uncertainty $\left(\varepsilon_{\mathrm{i}}\right)$ increases allowing "good" banks to correctly predict the expected return/risk of different investments, in the following periods the riskiness of those banks should be significantly lower than that of poorly informed intermediaries. Therefore, the variance of the non-performing loans ratio across intermediaries should widen. Of course, the NPL ratio is also affected by systemic factors; however, its cross-sectional dispersion may still provide some useful 
insight regarding hypothesis 2). The expected sign of this variable is positive. Since the variable may be endogenous, in the estimation it is instrumented with the lagged value of STDNPL.

Second, I use the first moment of inflation (INFL) and industrial production growth (INDPRODC) in order to control for the overall macroeconomic conditions and to test the robustness of the results in the presence of the levels of the variables (Huizinga, 1993). Inflation is frequently found as an indicator of macroeconomic mismanagement; high inflation may therefore, per se, imply uncertainty on the future. A negative coefficient is therefore my a priori belief. By contrast, it is not immediately clear the impact of industrial production growth on the dependent variable. Indeed, it is difficult to say whether in good times banks tend to behave more or less homogeneously.

Lastly, I introduce a variable (SHAREC) aiming at assessing the impact of the conditions on financial markets, since this is another factor that may influence banks' decisions. This variable is the quarterly rate of change of the "all shares" index calculated by the OECD from daily closing quotations.

Tables 6, 7 and 8 summarize the variables used in the estimations, show the main descriptive statistics of the regressors and illustrate the pair-wise correlations between the variables. It is interesting to note that the correlations between the dispersion of the loan-to-asset ratio - both in terms of variance and coefficient of variation - and uncertainty measures are negative and statistically significant at the 5 per cent level.

[Insert tables 6, 7, 8 here] 
Table 9 presents the instrumental-variable regression results. Newey-West standard errors are calculated assuming an autocorrelation up to the order 4.

\section{[Insert table 9 here]}

In both the specification, the proxies for macroeconomic uncertainty show the expected negative sign and are statistically significant, although their economic relevance is different. In particular, the magnitude of the coefficient on INFLVA (-1.23) suggests that this variable is an important determinant of LTA dispersion.

Overall, this confirms that Italian banks behave more homogenously when the perspectives of the economy are unclear. This is consistent with the evidence regarding US and Canadian banks reported respectively by Baum et al. (2004) and Garcia and Calmes (2005) and with the results of Beaudry et al. (2001) for UK non-financial firms.

However, it is worth pointing out that, with aggregate data, no inference can be drawn on the allocation of funds to particular loans and hence the credit risk of the loan book. In other words, the model implicitly assumes that bank's loan portfolio is homogenous. These assumptions should be ideally tested providing results for several loan categories, along with the aggregate ones ${ }^{7}$. Unfortunately, due to data limitations, this is not feasible at this stage.

The proxy for idiosyncratic uncertainty is also statistically significant and takes on a positive sign. When the returns on specific investments are less easily predictable, better informed banks can exploit their competitive advantage and behave in a different way with respect to poorly informed intermediaries.

\footnotetext{
${ }^{7}$ I am grateful to the referee for raising this point.
} 
In sum, results confirm that systemic uncertainty, both on the real and the financial side of the economy, induces intermediaries to herding behaviour. In contrast, individual uncertainty leads banks to behave more heterogeneously when deciding the allocation of their assets.

As far as the other control variables are concerned, industrial production growth is never significant. The inclusion of different variables aiming at controlling for the evolution of the business cycle, such as the leading indicator, demand and consumption growth or changes in the interest rates, does not change this evidence. This result indicates that the level of aggregate economic activity does not have any impact on the cross-sectional variability of the share that banks decide to invest in risky loans. However, the significance of the control variables must be interpreted with caution since the proxy for uncertainty is a generated regressor and the coefficient on it is significantly different from zero (Pagan, 1984; Oxley and McAleer, 1993).

The coefficient on inflation is not significant as well. The changes of the stock exchange index are slightly significant in the model with industrial production uncertainty.

\subsection{Robustness checks}

\subsubsection{Size breakdowns}

The dataset with banks' size breakdowns is used for robustness checks. The model is estimated using panel data techniques that exploit the cross-sectional dimension and allow obtaining more robust results ${ }^{8}$. For the estimation, I can exploit

\footnotetext{
${ }^{8}$ In principle, if bank's size is a proxy for the type of loans a bank grants, the evidence provided in this section might partly overcome the shortcomings related to loan heterogeneity mentioned above.
} 
300 observations (60 quarters / 5 size breakdowns). The results of the random effect model are presented in table 10.

\section{[Insert table 10 here]}

They appear consistent with those obtained in the previous paragraph. Macroeconomic uncertainty has a significant negative impact on the cross-bank dispersion of the loan-to-asset ratio, while the proxy for idiosyncratic uncertainty shows a positive sign. In these specifications, industrial production growth is significant, though at the 10 per cent level, and takes on a negative sign. According to this evidence, banks would take more uniform portfolio decisions during expansions. Inflation remains not significant, contrasting the idea that higher inflation levels are perceived as signals of economic turmoil. The Hausman tests for both the regressions imply that the random effects are appropriate for this sample.

\subsubsection{Uncertainty based on the one-step ahead forecast error}

In this paragraph, I use a different proxy for macroeconomic uncertainty in order to check whether my previous results are robust to different measures. The metric proposed here is based on the 1-step ahead forecast errors of the autoregressive models of industrial production growth and inflation. As suggested by Serven (1998), to ensure that the predictions use no more information than that available at the time they are formulated, they are computed from recursive estimation of the autoregressions. Therefore, for each variable, I estimate recursively the following auto-regressive model of order 2:

Unfortunately, this is not necessarily the case, since Italian banks are not specialized according to their size. 


$$
y_{t}=\beta_{0}+\beta_{1} y_{t-1}+\beta_{2} y_{t-2}+v_{t}
$$

The initial length of the series is set at 50. Since the dataset contains 362 observations (quarters) and I introduce 2 lags, I estimate 310 (362-2-50) regressions, in order to compute the 1-step ahead forecast errors. Using the recursive parameter estimates, I finally obtain the alternative uncertainty measure as the quarterly mean absolute values of the monthly one-step ahead forecast errors for industrial production and inflation (respectively INDPRODFE and INFLFE).

Table 11 provides the results of the regression of LTA variation coefficient on INDPRODFE and INFLFE.

\section{[Insert table 11 here]}

The role of uncertainty is confirmed by this exercise. Both additional proxies for macroeconomic uncertainty are statistically significant and negative. In particular, inflation unpredictability seems to be the most relevant determinant of banks' herding behaviours. Idiosyncratic uncertainty remains significantly positive.

\section{CONCLUSIONS}

This paper tries to disentangle which are the determinants of banks' decisions regarding the allocation of their portfolios; in particular it aims at assessing whether macroeconomic uncertainty plays a role in this choice. Following the portfolio model proposed by Baum et al., I discuss how Italian banks choose between loans and riskfree assets when the uncertainty on macroeconomic conditions increases. With respect to previous work, which neglects the role of idiosyncratic factors, the impact of 
macroeconomic uncertainty is assessed, taking also into account bank-specific sources of uncertainty.

The econometric results confirm that macroeconomic uncertainty does have a role in Italian banks' investment decisions. In periods of increasing turmoil, banks receive noisier signals on the expected returns of loans and, therefore, tend to behave more homogeneously, as shown by the reduction of the cross-sectional dispersion of the loan-to-asset ratio. A plausible corollary is that the allocation of bank credit becomes less efficient. Idiosyncratic uncertainty is also relevant and its coefficient takes on a positive sign. When the returns on specific investments are less easily predictable, better informed banks can exploit their competitive advantage and behave in a different way with respect to poorly informed intermediaries. These results are generally confirmed when bank size breakdowns are employed in the estimation. Furthermore, they are robust to the inclusion of several control variables and the use of different measures of macroeconomic uncertainty.

Macroeconomic uncertainty is therefore an important determinant of banks' lending decisions and a cause of potential disturbances in financial resource allocation. Since bank loans are a relevant source of financing for the non-financial sector, central banks and supervisory authorities should monitor the degree of uncertainty on the evolution of the main economic aggregates in order to strengthen macroeconomic and financial stability. 


\section{REFERENCES}

Baum C., Caglayan M. and Ozkan N. (2005), "The second moments matter: The response of bank lending behavior to macroeconomic uncertainty", Boston College - Working Paper, 521.

Beaudry P, Caglayan M. and Schiantarelli F. (2001), "Monetary Instability, the Predictability of Prices, and the Allocation of Investment: An Empirical Investigation Using UK Panel Data”, American Economic Review, Vol. 91, n. 3.

Bikker J. A. and Hu H. (2002), “Cyclical Patterns in Profits, Provisioning and Lending of Banks”, DNB Staff Reports, n. 86, Amsterdam.

Bollerslev T. (1986), "Generalized autoregressive conditional heteroskedasticity”, Journal of Econometrics, Vol. 31, n. 3.

Bomberger W. A. (1996), "Disagreement as a Measure of Uncertainty", Journal of Money, Credit and Banking, Vol. 28, n. 3.

Carruth A., Dickerson A. and Henley A. (2000), "What Do We Know about Investment under Uncertainty?”, Journal of Economic Surveys, Vol. 14, n. 2.

Ciocca P. (2004), “The Italian Financial System Remodelled”, Palgrave Macmillan.

Cotula F. (1989), “La politica monetaria in Italia”, Vol. II, Il Mulino.

Driver C., Trapani L. and Urga G. (2004), “Cross-Section vs. Time Series Measures of Uncertainty using UK Survey Data”, Royal Economic Society Annual Conference 2004.

Enders W. (1995), Applied Econometrics - Time Series, John Wiley \& Sons, New York.

Engle R. (1982), “Autoregressive Conditional Heteroskedasticity with Estimates of the Variance of United Kingdom Inflation”, Econometrica, Vol.50, n. 4.

Gambera M. (2000), “Simple Forecasts of Bank Loan Quality in the Business Cycle”, Federal Reserve Bank of Chicago, Supervision and Regulation Department, Emerging Issues Series, S\&R-2000-3, Chicago.

Garcia A. and Calmes C. (2005), "Banks Lending and Macroeconomic Uncertainty: The Case of Canada”, Bank of Canada - Working Paper, n. 28.

Grier K. B. and Perry M. J. (2000), "The Effects of Real and Nominal Uncertainty on Inflation and Output Growth: Some GARCH-M Evidence”, Journal of Applied Econometrics, Vol. 15, n. 1.

Hoggarth G., Sorensen S. and Zicchino L. (2005), "Stress tests of UK banks using a VAR approach”, Bank of England, working paper, n. 282.

Huizinga J. (1993), “Inflation Uncertainty, Relative Price Uncertainty, and Investment in U.S. Manufacturing”, Journal of Money, Credit and Banking, Vol. 25, n.3. 
Laeven L. and Majoni G. (2003), “Loan Loss Provisioning and Economic Slowdowns: Too Much, Too Late?”, Journal of Financial Intermediation, Vol. 12, n. 2.

Meyer A. P. and Yeager T. J. (2001), “Are small Rural Banks Vulnerable to Local Economic Downturns?”, Federal Reserve Bank of St. Louis Review.

Oxley L. and McAleer M. (1993), "Econometric issues in macroeconomic models with generated regressors", Journal of Economic Surveys, Vol. 7, n. 1.

Pagan A. (1984), "Econometric Issues in the Analysis of Regressions with Generated Regressors”, International Economic Review, Vol. 25, n. 1.

Pagan A. and Ullah A. (1988), "The Econometric Analysis of Models With Risk Terms”, Journal of Applied Econometrics, Vol. 3, n. 2.

Pesola J. (2001), “The role of macroeconomic shocks in banking crises”, Bank of Finland Discussion Papers, n. 6, Helsinki.

Quagliariello M. (in press, a), "Does Macroeconomy Affect Bank Stability? A Review of the Empirical Evidence”, forthcoming in the Journal of Banking Regulation.

Quagliariello M. (in press, b), “Banks’ riskiness over the business cycle: a panel analysis on Italian intermediaries”, forthcoming in Applied Financial Economics.

Salas V. and Saurina J. (2002), "Credit risk in two institutional settings: Spanish commercial and saving banks”, Journal of Financial Services Research, Vol. 22, issue 3, December, 203-224.

Sepulveda-Umanzor J. (2004), “The Relation between Macroeconomic Uncertainty and the Expected Performance of the Economy”, North Caroline State University, mimeo.

Serven L. (1998), "Macroeconomic Uncertainty and Private Investment in LDCs: An Empirical Investigation”, World Bank Country Economics Department Series, n. 2035.

Valckx N. (2003), “What determines loan loss provisioning in the EU?”, ECB, mimeo.

Zarnowitz V. and Lambros L. A. (1987), "Consensus and Uncertainty in Economic Prediction”, Journal of Political Economy, Vol. 95, n. 3. 


\section{ACKOWLEDGEMENTS}

I am grateful to F. Cannata, A. De Vincenzo, C. Guerzoni, S. Iannotti, J. Marcucci for their comments. An anonymous referee provided very helpful suggestions for improving the paper. My special thanks go to P. N. Smith for his continuous guidance. All remaining errors are my own. The opinions expressed herein are those of the author and do not necessarily reflect those of Banca d'Italia. 
TABLES AND FIGURES

Table 1

\begin{tabular}{ccc}
\hline \hline \multicolumn{3}{c}{ THE SAMPLES: SUMMARY } \\
\hline \hline & $\begin{array}{c}\text { no. banks per quarter } \\
\text { (average) }\end{array}$ & no. obs \\
FULL SAMPLE & 953 & 58146 \\
MAJOR BANKS & 14 & 870 \\
LARGE BANKS & 16 & 972 \\
MEDIUM BANKS & 36 & 2203 \\
SMALL BANKS & 143 & 8740 \\
MINOR BANKS & 744 & 45361 \\
TIME-SPAN & 1 st quarter 1990 - 1st quarter 2005 \\
\hline
\end{tabular}

Editorial Office, Dept of Economics, Warwick University, Coventry CV4 7AL, UK 
Table 2

\begin{tabular}{|c|c|c|c|c|c|}
\hline \multicolumn{6}{|c|}{ LOAN-TO-ASSET RATIO: SIZE BREAKDOWN } \\
\hline Variable & N. obs & Mean & STD & Min & Max \\
\hline \multicolumn{6}{|c|}{ TOTAL } \\
\hline LTA & 61 & 44.81 & 6.68 & 36.23 & 58.10 \\
\hline STDLTA & 61 & 15.81 & 3.91 & 10.51 & 21.52 \\
\hline CVLTA & 61 & 0.35 & 0.04 & 0.27 & 0.40 \\
\hline \multicolumn{6}{|c|}{ Major Banks } \\
\hline LTA & 61 & 44.16 & 4.33 & 32.95 & 51.58 \\
\hline STDLTA & 61 & 13.12 & 8.56 & 4.00 & 28.47 \\
\hline CVLTA & 61 & $\begin{array}{c}0.29 \\
\text { Large }\end{array}$ & 0.18 & 0.09 & 0.62 \\
\hline LTA & 61 & 46.57 & 3.27 & 39.38 & 53.89 \\
\hline STDLTA & 61 & 14.39 & 6.98 & 4.67 & 28.26 \\
\hline CVLTA & 61 & 0.31 & 0.14 & 0.10 & 0.63 \\
\hline \multicolumn{6}{|c|}{ Medium Banks } \\
\hline LTA & 61 & 50.00 & 7.27 & 37.79 & 62.92 \\
\hline STDLTA & 61 & 16.53 & 4.18 & 7.56 & 22.01 \\
\hline \multicolumn{6}{|c|}{ Small Banks } \\
\hline LTA & 61 & 48.28 & 7.82 & 36.87 & 62.90 \\
\hline STDLTA & 61 & 19.00 & 5.13 & 10.55 & 24.43 \\
\hline \multicolumn{6}{|c|}{ Minor Banks } \\
\hline LTA & 61 & 43.86 & 6.51 & 35.86 & 57.34 \\
\hline STDLTA & 61 & 14.85 & 3.62 & 10.33 & 20.68 \\
\hline CVLTA & 61 & 0.33 & 0.04 & 0.27 & 0.40 \\
\hline
\end{tabular}

Notes: LTA is the average of the loan-to-asset ratio; STDLTA is the cross-sectional variance of the loan-to-asset-ratio; CVLTA is the cross-sectional coefficient of variation of the loan-toasset-ratio. 
Table 3

ADF TESTS FOR UNIT ROOTS (1)

\begin{tabular}{ccccc}
\hline \hline Variable & Z(t) statistics & \multicolumn{3}{c}{ Interpolated Dickey-Fuller } \\
& & $1 \%$ critical value & $5 \%$ critical value & $10 \%$ critical value \\
INDPRODC (2) & $-6.512^{* * *}$ & -3.452 & -2.876 & -2.57 \\
INFL (3) & $-4.532^{* * *}$ & -3.986 & -3.426 & -3.13 \\
LEADINDC (4) & $-5.657^{* * *}$ & -2.58 & -1.95 & -1.62 \\
\hline
\end{tabular}

$*, * *, * * *$ significant at the 10,5 and 1 per cent level respectively.

Notes: (1) Augmented Dickey Fuller test for unit root. Selection of the auxiliary regression via general-to-simple procedure. (2) 5 lags and drift included in the regression. (3) 5 lags, trend and drift included in the regression.

(4) 5 lags included in the regression.

Table 4

\section{LM TEST FOR ARCH EFFECTS (1)}

\begin{tabular}{ccccc}
\hline \hline \multirow{2}{*}{ Variable } & \multicolumn{2}{c}{ ARCH(1) } & \multicolumn{2}{c}{ ARCH(4) } \\
& Chi-squared & df & Chi-squared & df \\
INDPRODC & $14.206^{* * *}$ & 1 & $24.606^{* * *}$ & 4 \\
INFL & $3.833^{* *}$ & 1 & $52.922^{* * *}$ & 4 \\
LEADINDC & 0.005 & 1 & 6.928 & 4 \\
\hline
\end{tabular}

*, **, *** significant at the 10, 5 and 1 per cent level respectively.

Notes: (1) Lagrange Multiplier test for ARCH effects. 4 lags included in the auxiliary autoregression. 
Table 5a

\begin{tabular}{l|ccc}
\hline \hline \multicolumn{3}{c}{ ESTIMATION OF MACROECONOMIC UNCERTAINTY } \\
GARCH (1,1) FOR INDUSTRIAL PRODUCTION GROWTH \\
\hline \hline \\
\hline Mean equation & Coefficient & Semi-robust SE & Sign. lev. \\
INDPRODC (LAG1) & -0.2152 & 0.0602 & $* * *$ \\
CONSTANT & 0.0793 & 0.0639 & \\
Variance equation & & & \\
ARCH(1) & 0.0462 & 0.0187 & $* *$ \\
GARCH(1) & 0.9449 & 0.0158 & $* * *$ \\
CONSTANT & 0.0012 & 0.0067 & \\
Nr. Obs. & 361 & & \\
Wald Chi-squared & Chi2(1)=12.78 & \\
Log pseudo-likelihood & $-630,765$ & \\
LM ARCH 1-12 & $\mathrm{F}(12,332)=0.37746$ & \\
\hline
\end{tabular}

*, **, *** significant at the 10,5 and 1 per cent level respectively.

Notes: Lagrange Multiplier test for ARCH effects is reported.

Table 5b

\begin{tabular}{c}
\hline \hline ESTIMATION OF MACROECONOMIC UNCERTAINTY \\
GARCH (1,1) FOR CPI INFLATION \\
\hline \hline
\end{tabular}

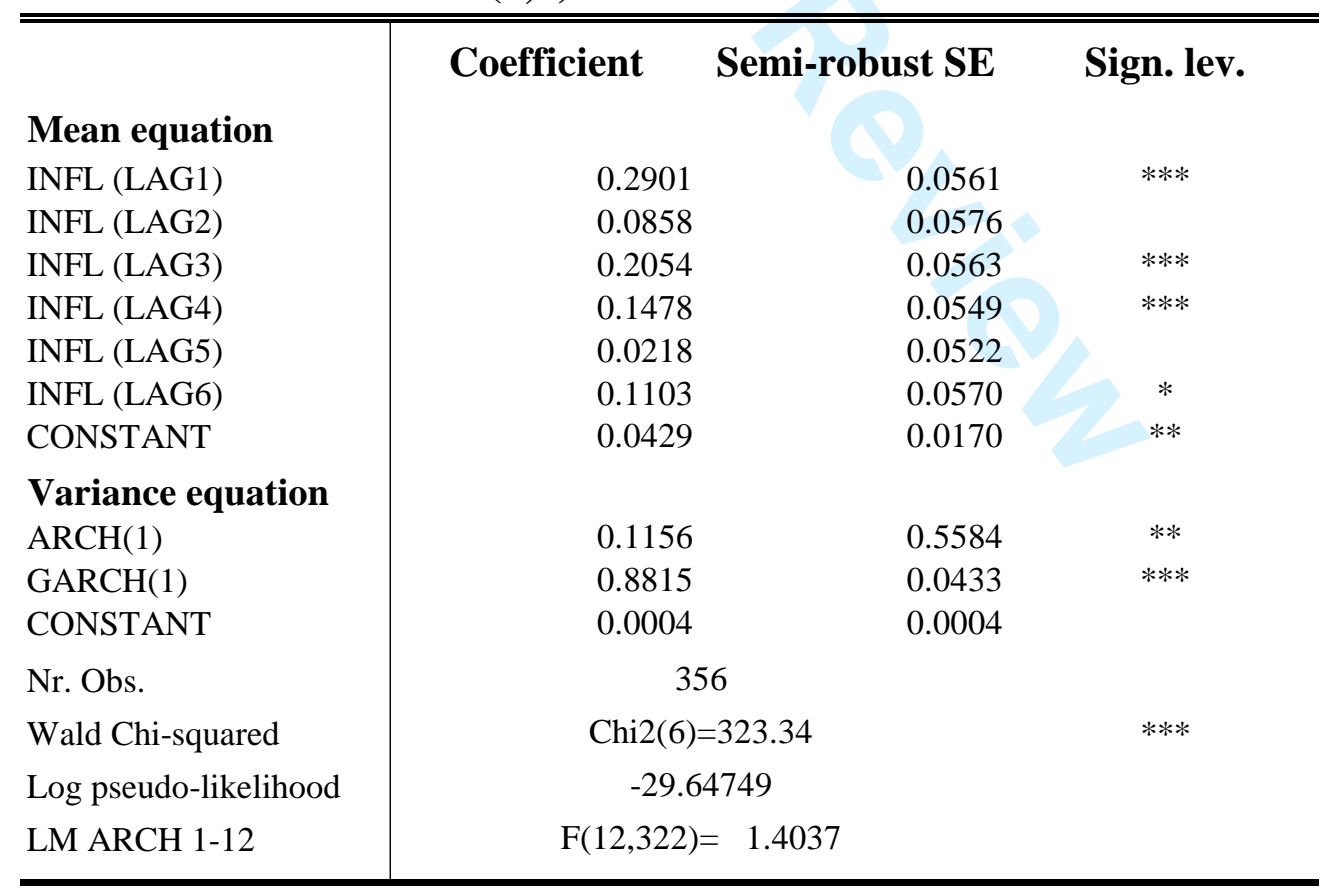

*, **, *** significant at the 10,5 and 1 per cent level respectively.

Notes: Lagrange Multiplier test for ARCH effects is reported. 
Table 6

\begin{tabular}{ccc}
\hline \hline & SELECTED VARIABLES & \\
\hline \hline Name & Description & Source \\
LTA & Loan-to-asset ratio (\%) & BoI Sup.statistics \\
STDLTA & Cross-sectional STD of LTA (\%) & BoI Sup.statistics \\
CVLTA & Coefficient of variation of LTA (STDLTA/MLTA) & BoI Sup.statistics \\
STDNPL & Cross-sectional STD of non-performing loan ratio (\%) & BoI Sup.statistics \\
INDPRODC & Industrial production change (\%) & OECD \\
INFL & CPI inflation (\%) & OECD \\
SHAREC & Share price change (\%) & OECD \\
INDPRVA & Conditional variance of INDPRODC & OECD \\
INFLVA & Conditional variance of INFL & OECD \\
\hline
\end{tabular}

Table 7

REGRESSORS: DESCRIPTIVE STATISTICS

\begin{tabular}{crrrrr}
\hline \hline Variable & N. obs & Mean & STD & Min & Max \\
STDNPL & 61 & 9.24 & 0.93 & 7.60 & 11.26 \\
INDPRODC & 61 & 0.04 & 0.53 & -1.18 & 1.19 \\
INFL & 61 & 0.28 & 0.16 & 0.03 & 0.69 \\
SHAREC & 61 & 0.60 & 3.80 & -8.15 & 11.67 \\
INDPRVA & 61 & 0.86 & 0.37 & 0.41 & 2.22 \\
INFLVA & 61 & 0.03 & 0.01 & 0.01 & 0.06 \\
\hline
\end{tabular}

Table 8

\begin{tabular}{lrrrrrr}
\hline \hline \multicolumn{7}{c}{ CORRELATION COEFFICIENTS } \\
\hline \hline & LTA & STDLTA & CVLTA & STDNPL & INDPRVA & INFLVA \\
LTA & 1.000 & & & & & \\
STDLTA & $\mathbf{0 . 9 4 8}$ & 1.000 & & & & \\
CVLTA & $\mathbf{0 . 6 9 6}$ & $\mathbf{0 . 8 8 8}$ & 1.000 & & & \\
STDNPL & 0.150 & $\mathbf{0 . 3 9 8}$ & $\mathbf{0 . 7 0 0}$ & 1.000 & & \\
INDPRVA & $\mathbf{- 0 . 6 2 0}$ & $\mathbf{- 0 . 6 7 6}$ & $\mathbf{- 0 . 6 3 7}$ & $\mathbf{- 0 . 4 1 5}$ & 1.000 & \\
INFLVA & $\mathbf{- 0 . 7 7 7}$ & $\mathbf{- 0 . 7 2 8}$ & $\mathbf{- 0 . 5 2 6}$ & -0.208 & $\mathbf{0 . 7 5 7}$ & 1.000 \\
\hline
\end{tabular}

Coefficients in bold are significant at the 5 per cent level. 
Table 9

\begin{tabular}{|c|c|c|c|c|c|c|}
\hline \multicolumn{7}{|c|}{ ECONOMETRIC RESULTS } \\
\hline \multicolumn{7}{|c|}{ INSTRUMENTAL VARIABLE REGRESSION OF CV(LTA) } \\
\hline \multirow[b]{2}{*}{$\begin{array}{l}\text { Explanatory } \\
\text { variables }\end{array}$} & \multicolumn{3}{|c|}{$\begin{array}{l}\text { Uncertainty on industrial } \\
\text { production }\end{array}$} & \multicolumn{3}{|c|}{ Uncertainty on inflation } \\
\hline & Coeffic. & N-W SE & Sign. lev. & Coeffic. & N-W SE & Sign. lev. \\
\hline intercept & 0.1028 & 0.1099 & & 0.0868 & 0.0953 & \\
\hline INDPRVA & -0.0395 & 0.0187 & $* *$ & - & & \\
\hline INFLVA & - & - & & -1.2254 & 0.4394 & $* * *$ \\
\hline LEAD(STDNPL) & 0.0311 & 0.0101 & $* * *$ & 0.0334 & 0.0090 & $* * *$ \\
\hline INFL & -0.0230 & 0.0312 & & -0.0264 & 0.0323 & \\
\hline INDPRODC & -0.0132 & 0.0085 & & -0.0126 & 0.0083 & \\
\hline SHAREC & -0.0014 & 0.0008 & * & -0.0010 & 0.0007 & \\
\hline Nr. Obs. & 60 & & & 60 & & \\
\hline F-test & $F(5,54)=$ & 12.39 & $* * *$ & $\mathrm{~F}(5,54)$ & 16.40 & $* * *$ \\
\hline
\end{tabular}

$*, * *, * * *$ significant at the 10,5 and 1 per cent level respectively. The estimated regressions are:

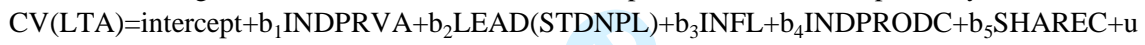

$C V(L T A)={\text { intercep } t+b_{1} I N F L V A+b_{2} L E A D(S T D N P L)}+b_{3} I N F L+b_{4}$ INDPRODC $+b_{5}$ SHAREC $+u$

Notes: Newey-West robust standard errors are reported; the errors are assumed to be heteroskedastic and autocorrelated up to 4 lags. LEAD(STDNPL) instrumented with LAG(STDNPL). 
Table 10

\begin{tabular}{|c|c|c|c|c|c|c|}
\hline \multicolumn{7}{|c|}{ ROBUSTNESS CHECKS } \\
\hline \multicolumn{7}{|c|}{ INSTRUMENTAL VARIABLE PANEL REGRESSION OF CV(LTA)(1) } \\
\hline & \multicolumn{3}{|c|}{ Uncertainty on industrial production } & \multicolumn{3}{|c|}{ Uncertainty on inflation } \\
\hline $\begin{array}{l}\text { Explanatory } \\
\text { variables }\end{array}$ & Coeffic. & SE & Sign. lev. & Coeffic. & SE & Sign. lev. \\
\hline intercept & 0.3180 & 0.0272 & $* * *$ & 0.3473 & 0.0267 & $* * *$ \\
\hline INDPRVA & -0.1080 & 0.0180 & $* * *$ & - & - & \\
\hline INFLVA & - & - & & -3.6291 & 0.4449 & $* * *$ \\
\hline LEAD(STDNPL) & 0.0150 & 0.0016 & $* * *$ & 0.0148 & 0.0015 & $* * *$ \\
\hline INFL & -0.0377 & 0.0418 & & -0.0566 & 0.0357 & \\
\hline INDPRODC & -0.0194 & 0.0092 & * & -0.0167 & 0.0088 & * \\
\hline SHAREC & -0.0009 & 0.0013 & & 0.0005 & 0.0012 & \\
\hline Nr. Obs. & \multicolumn{2}{|c|}{300} & & \multicolumn{2}{|c|}{300} & \\
\hline Wald-test & \multicolumn{2}{|c|}{ Chi2(5)=255.06 } & $* * *$ & \multicolumn{2}{|c|}{ Chi2(5)=294.35 } & $* * *$ \\
\hline R-squared (overall) & \multicolumn{2}{|c|}{0.437} & & \multicolumn{2}{|c|}{0.477} & \\
\hline Hausman-test & \multicolumn{2}{|c|}{ Chi2(5)=0.01 } & & \multicolumn{2}{|c|}{ Chi2(5) $=0.01$} & \\
\hline
\end{tabular}

$*, * *, * * *$ significant at the 10,5 and 1 per cent level respectively. The estimated regressions are: $C V(L T A)=$ intercep $+\mathrm{b}_{1}$ INDPRVA $+\mathrm{b}_{2} \mathrm{LEAD}(\mathrm{STDNPL})+\mathrm{b}_{3}$ INFL $+\mathrm{b}_{4}$ INDPRODC $+\mathrm{b}_{5}$ SHAREC $+\mathrm{a}+\mathrm{u}$ $\mathrm{CV}(\mathrm{LTA})=$ intercept $^{+} \mathrm{b}_{1}$ INFLVA $+\mathrm{b}_{2} \mathrm{LEAD}(\mathrm{STDNPL})+\mathrm{b}_{3} \mathrm{INFL}+\mathrm{b}_{4}$ INDPRODC $+\mathrm{b}_{5}$ SHAREC $+\mathrm{a}+\mathrm{u}$

Notes: (1) Random effect model. LEAD(STDNPL) instrumented with LAG(STDNPL). Hausman test for random effects is reported (Ho: RE). 
Table 11

\begin{tabular}{l|l|rrr}
\hline \hline \multicolumn{7}{c}{ ROBUSTNESS CHECKS } \\
IV REG. OF CV(LTA) WITH DIFFERENT PROXIES FOR UNCERTAINTY \\
\hline \hline
\end{tabular}

$*, * *, * * *$ significant at the 10,5 and 1 per cent level respectively. The estimated regressions are: $C V(L T A)=$ intercept $+b_{1}$ INDPRODFE $+b_{2}$ LEAD $(S T D N P L)+b_{3} I N F L+b_{4}$ INDPRODC $+b_{5}$ SHAREC $+u$

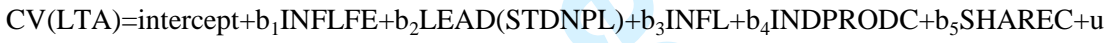

Notes: Newey-West robust standard errors are reported; the errors are assumed to be heteroskedastic and autocorrelated up to 4 lags. LEAD(STDNPL) instrumented with LAG(STDNPL). 
Fig. 1 LOAN-TO-ASSET RATIO

(percentage values)

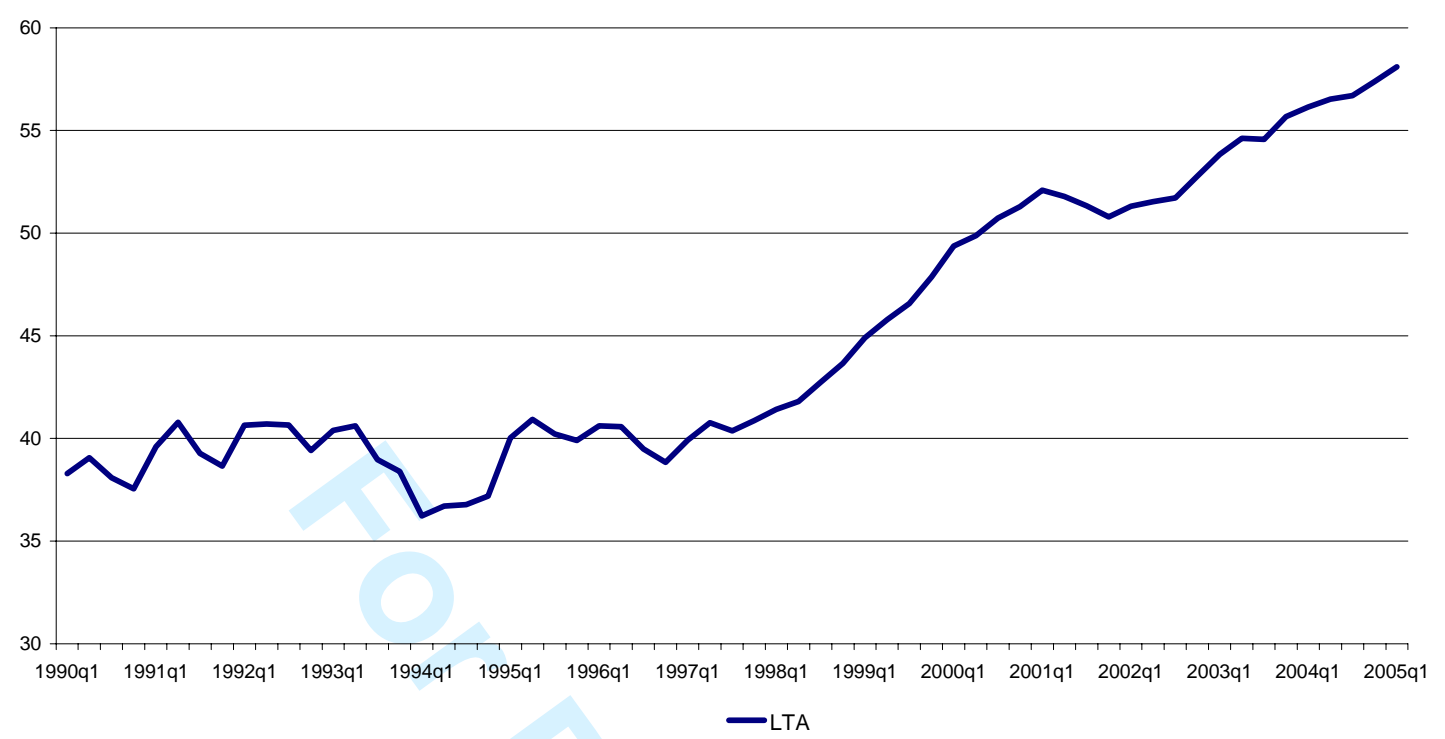

Fig. 2 CROSS-SECTIONAL DISPERSION OF LTA: SIZE BREAKDOWN (coefficient of variation, percentage values)

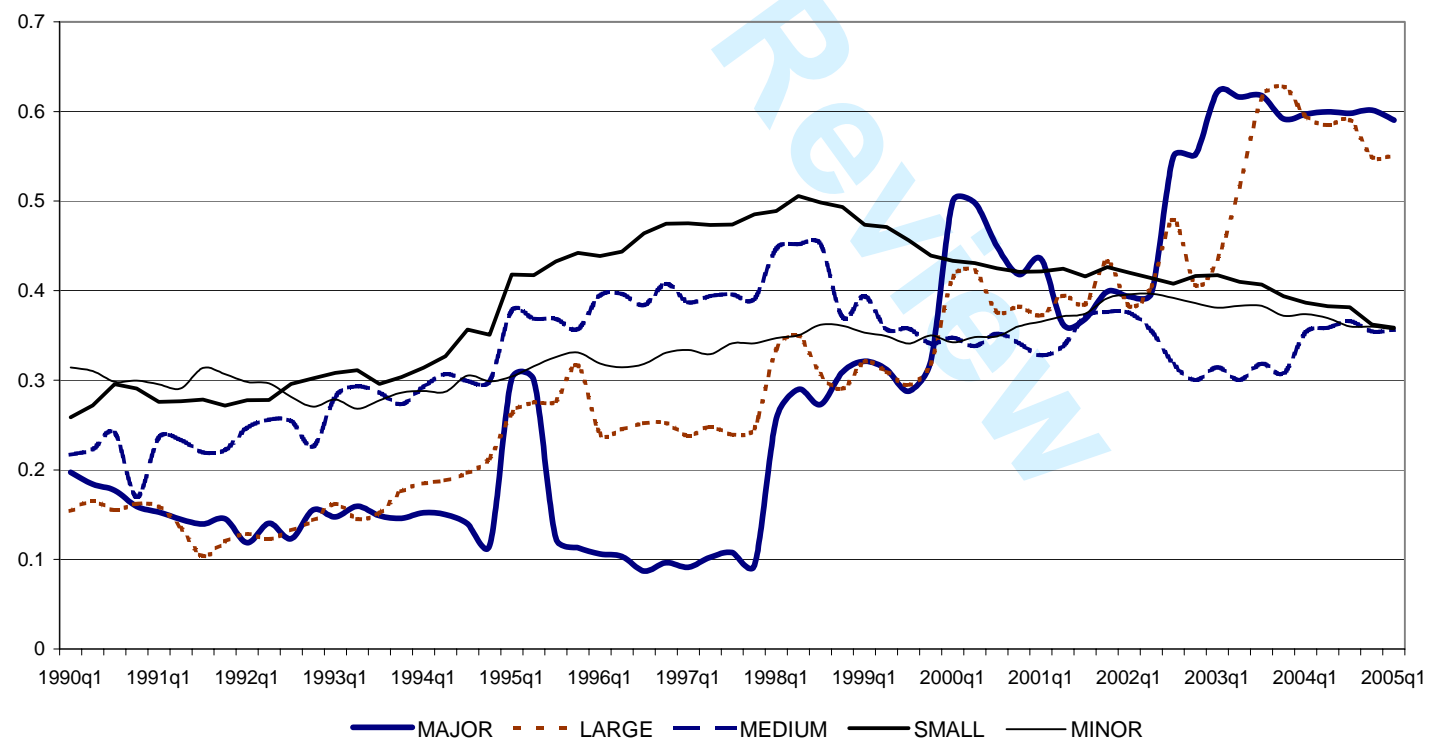


Fig. 3 CROSS-SECTIONAL DISPERSION OF LTA vs. INDUSTRIAL PRODUCTION UNCERTAINTY

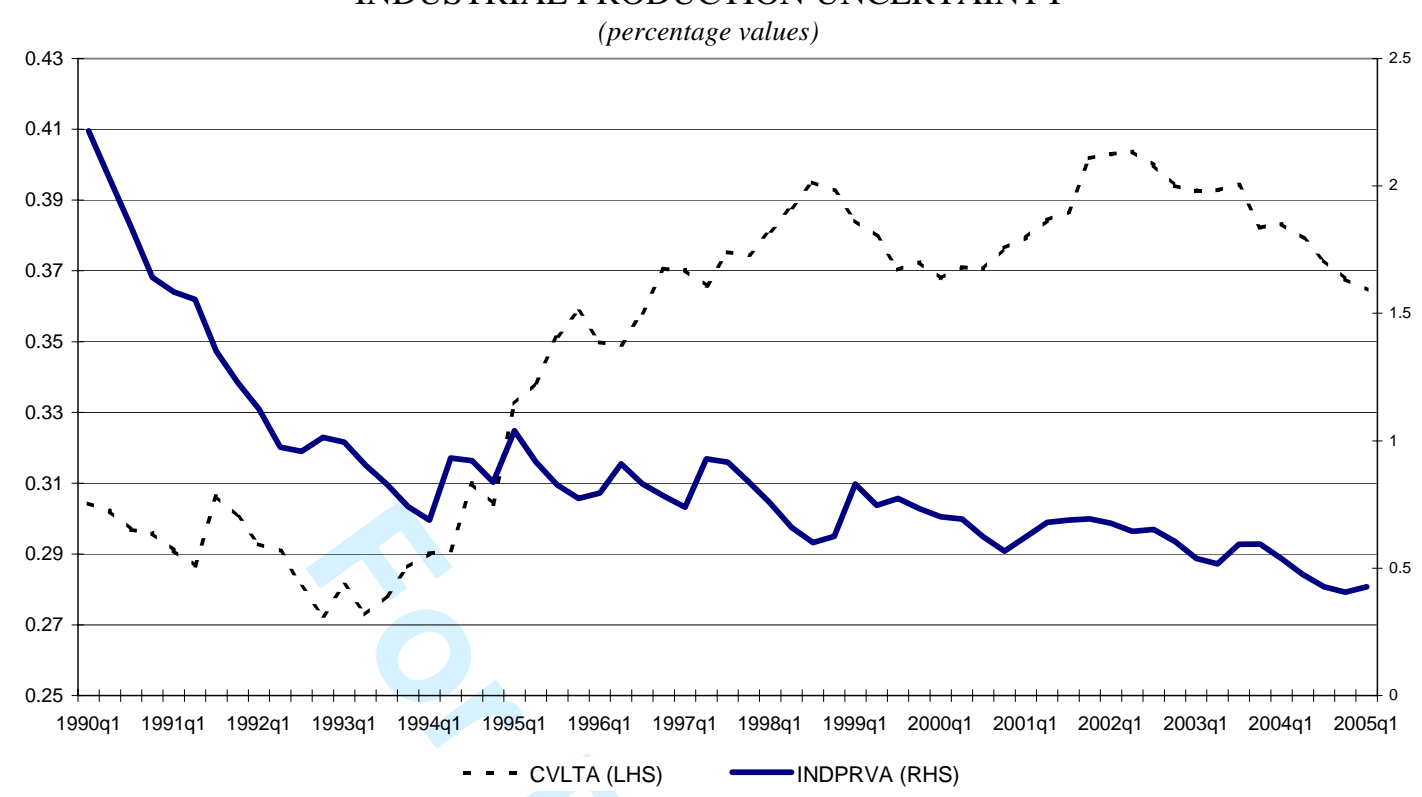

Fig. 4 CROSS-SECTIONAL DISPERSION OF LTA vs. INFLATION UNCERTAINTY

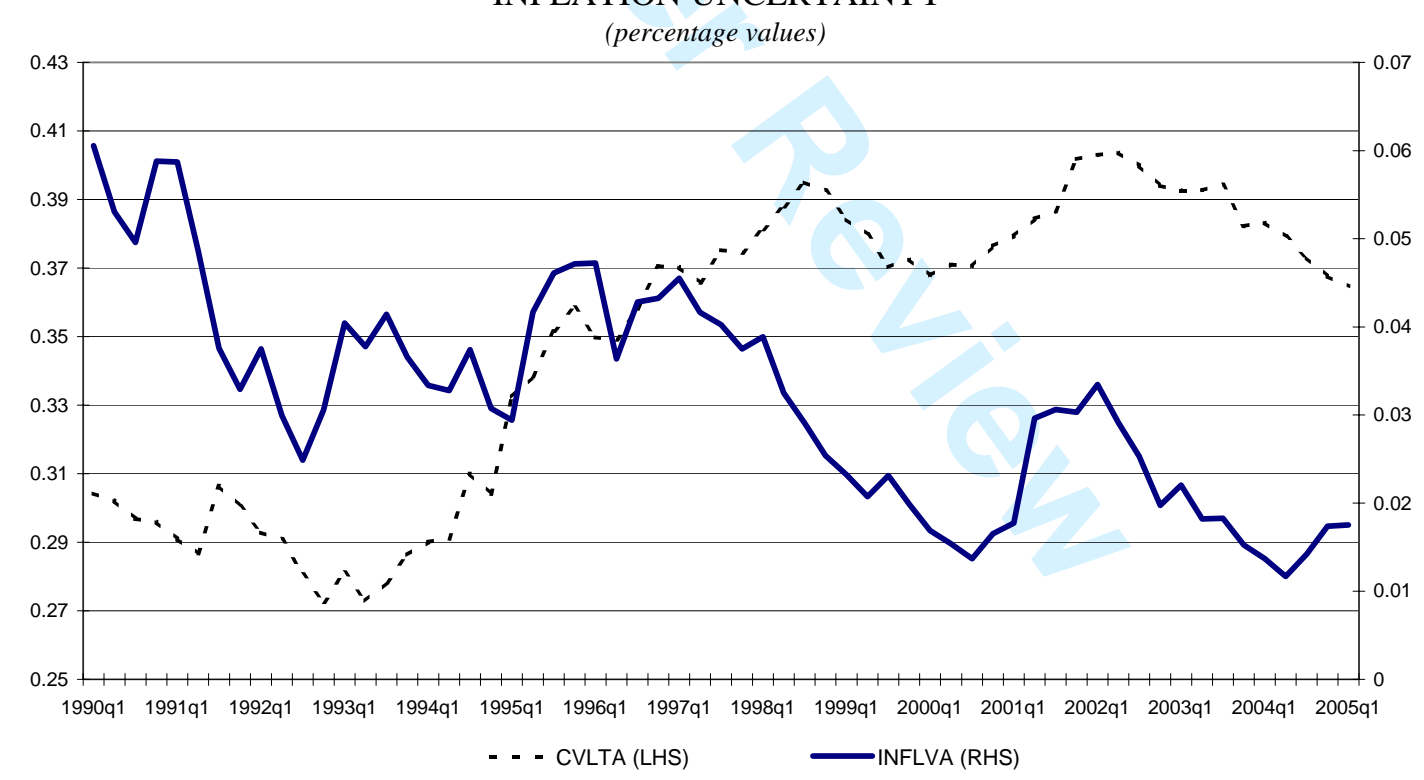

